\title{
NETWORKS AND MECHANISMS OF INTERDEPENDENCE Theoretical Developments beyond the Rational Action Model
}

\section{REDES Y MECANISMOS DE INTERDEPENDENCIA \\ Desarrollos teóricos más allá de los modelos de acción racional}

\author{
SAndRA GonzÁlez-BAilón* \\ Oxford Internet Institute and Nuffield College. University of Oxford \\ sandra.gonzalezbailon@oii.ox.ac.uk
}

\begin{abstract}
There is interdependence when the actions of an individual influence the decisions (and later actions) of other individuals. This paper claims that social networks define the structure of that range of influence and unleash a number of mechanisms that go beyond those captured by rational action theory. Networks give access to the ideas and actions of other individuals, and this exposure determines the activation of thresholds, the timing of actions, and the emergence of contagion processes, informational cascades and epidemics. This paper sustains that rational action theory does not offer the necessary tools to model these processes if it is not inserted in a general theory of networks. This is especially the case in the context opened by new information and communication technologies, where the interdependence of individuals is acquiring greater empirical relevance.
\end{abstract}

\section{Additional KeYWORDS}

Cascades, Collective Action, Internet, Social Influence, Threshold.

\section{RESUMEN}

Existe interdependencia cuando las acciones de unos individuos influyen en las decisiones (y posteriores acciones) de otros individuos. Este artículo sostiene que las redes sociales definen la estructura de ese espacio de influencia y desatan una serie de mecanismos de los que la teoría de la elección racional no puede dar cuenta. Las redes sociales abren acceso a las ideas y acciones de otros individuos, y esta exposición determina la satisfacción de umbrales, el tempo con en el que se llevan a cabo las acciones y la emergencia de procesos de contagio, cascadas de información y epidemias. Este artículo defiende que la teoría de la elección racional no ofrece las herramientas necesarias para modelizar tales procesos si no se inserta en una teoría general de redes. Éste es especialmente el caso en unos momentos en los que la interdependencia de individuos está adquiriendo, al amparo de las nuevas tecnologías, mayor relevancia empírica.

\section{Palabras Clave Adicionales}

Acción colectiva, Cascadas, Influencia Social, Internet, Umbrales. 


\section{INTRODUCTION}

Rational action theory (RAT) and the analytical tools developed under its umbrella (in particular, game theory) has contributed to advance our understanding of social phenomena such as collective action or the emergence of norms (Olson 1965; UllmannMargalit 1977; Hardin 1982; Axelrod 1984; Elster 1989; Coleman 1990; also Aguiar 1990; Linares 2004; Miller 2007). By uncovering and formalising the micro-foundations on which collective dynamics are based, RAT has contributed to the generalisation of a powerful explanatory framework; however, its models have seldom taken into account the role (often counterintuitive) played by interdependence and by the network of interactions from where individuals decide and act. Networks open the channels through which social influence flows: they create the basic infrastructure that allows the formation of preferences or the emergence of social norms. An efficient and global diffusion of information, for instance, depends on the structure of the network connecting individuals: some are more efficient than others in spreading the reputation of future partners of interaction or in facilitating the enforcement of norms.

This paper aims to justify two claims: first, that RAT needs to be inserted in a general theory of networks if it is to explain the emergence of social processes like collective action; and second, that RAT models will be more relevant empirically if they make explicit assumptions about the networks that connect individuals, particularly in the light of recent episodes of mobilisation facilitated by the use of new technologies. The assumption that underlies these claims is that individuals do not decide or act in isolation: they observe what other individuals do and are influenced by their actions. This interdependence unfolds mechanisms that cannot be reduced to the analytical framework proposed by RAT: two choices or actions that are identical from the point of view of an individual might unleash completely different consequences depending on how those individuals are positioned in a global network of interactions (Goyal 2007: 25-26). The argument developed in this paper is not intended as a rebuttal of RAT models; instead, it aims to justify why it is necessary to insert them in a theory of networks.

\section{A Model to lllustrate the Explanatory Role of Networks}

Networks generate a complexity that lies beyond the scope of the models proposed by the RAT. The model represented in Figure 1, a form of cellular automaton (Gilbert and Troitzsch 2005: p.), aims to illustrate why. In this model each cell can exhibit two possible states, identified by the colours black and white. If we assume that each cell represents an individual and that each state represents a particular voting intention (if white, the vote will go for candidate $X$, and if black, it will go for candidate $Y$ ), the model allows us to analyse the impact that different rules of decision and social influence will have on the final distribution of votes. In this example, the decision rule is simple: agents will look around, they will count the number of neighbours that intend to vote white and those 
who intend to vote black, and will adopt the vote of the majority. What changes in the two scenarios represented in the figure is the definition of neighbourhood, that is, the number of neighbours that will influence a given agent when it comes to deciding which candidate to vote for. In scenario A agents take into account the eight neighbours surrounding them; in scenario $B$ they only take into account the agents placed in the four cardinal points $(\mathrm{N}$, $\mathrm{S}, \mathrm{E}$ and $\mathrm{W})$.

The patterns reproduced in the upper part of the figure result from the evolution of the model, the starting point of which is the same in both scenarios: a random distribution of vote intentions. Every time step, agents follow the majority rule, until the system reaches

Figure 1.

The Influence of Networks in Social Processes like the Distribution of Votes

A
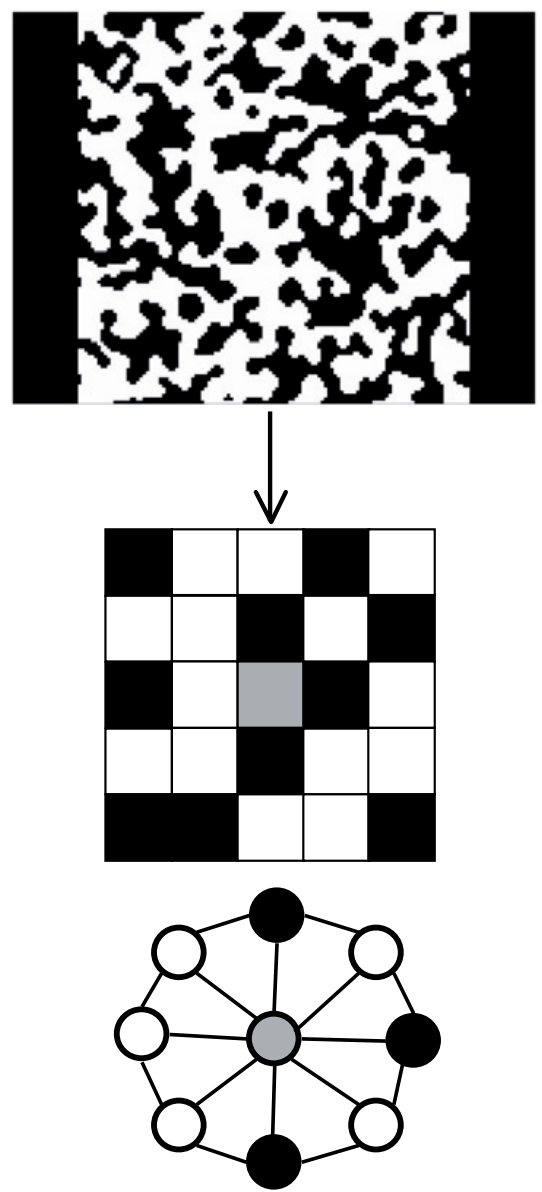

B
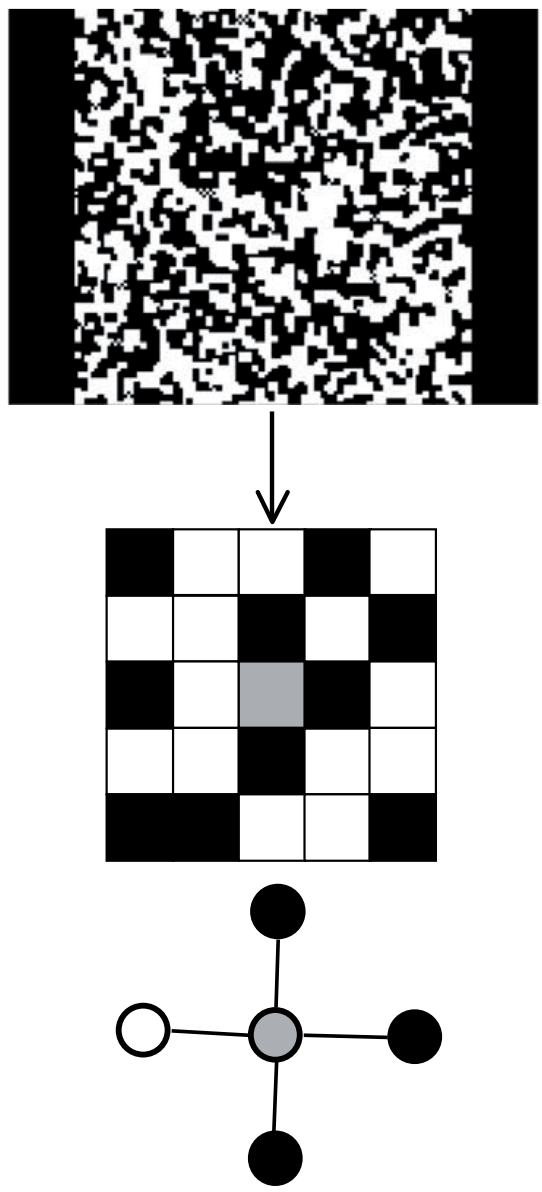
the equilibrium captured in the figure. As the figure shows, segregation is more extreme in the first scenario than in the second. This is arguably an obvious result given the specifications of the model. However, the evolution of this model hides mechanisms that are not so intuitive at first sight and that depend on the structure of the network underlying the interactions. The lower part of the figure reproduces the networks that operate in both scenarios for an hypothetical agent $Z$. Note that the configuration of the environment for this particular agent (represented by the grey cell) is identical in both cases; what changes is the network of contacts that the agent will observe when deciding how to cast her vote. In the first case, the neighbourhood includes a majority of white votes, but in the second case, the black vote predominates. As a result, agent $Z$ will choose white in scenario $A$ and black in scenario $B$.

In spite of its simplicity, this model captures one of the mechanisms that we can only identify if we analyse the networks that underlie agents' interactions, namely the exposure that agents have to the choices and actions of other agents. The agent in scenario A has a wider exposure than the agent in scenario $B$ simply because her network is larger. The expanded scope of influence to which agents in scenario $A$ are subjected generates a higher segregation of votes.

In addition to exposure, there are other network mechanisms that also influence social dynamics. This paper discusses these mechanisms by introducing, first, the theoretical debate about the role that networks play in the emergence of norms and collective action; the second section explores these network mechanisms in greater depth by considering different scenarios of interaction in which networks have been found to have a significant influence in individual and collective outcomes; the third section presents the mathematical models that have tried to formalise some of the relevant properties that networks have to exhibit to increase their efficiency and, finally, the paper concludes by discussing the impact that new technologies are having in the configuration and efficiency of social networks. Lines for future research are identified in the final section.

\section{The Importance of Networks for Collective Action}

Social capital is one of the theories that have long emphasized the explanatory role of networks, especially in its application to the analysis of civil society (Putnam 1995, 2000; Paxton 1999, 2002). According to this theory, social networks are important because they promote the flow of information, instil habits of cooperation, and encourage political engagement (Putnam 2000: 338). Social networks contribute to create "feelings of duty, increase a sense of interdependence with others, and produce a habit of participation" at the same time that they increase "the exposure of individuals to political ideas and debates" (Paxton 2002: 258-9). Social capital theory sees in civic communities horizontal structures in which trust, solidarity and participation take place in what would be unsustainable levels in the absence of dense networks. Networks contribute to the 
workings of civil society because they allow individuals to articulate communities based on norms, trust and reputation, that is, they enhance the auto-regulation of communities without the need of formalised authorities.

Networks, however, not only affect the strength of political engagement and the authority of civic communities. They are also structures that embody a distribution of power: networks open a differential access to the channels that facilitate the exchange of resources and the different positions that emerge from this "largely determine the relative power of each actor in the network" (Knoke 1990: 9-10). To this view, power takes the form of centrality and prestige within the network, and it has political consequences because it affects the role actors have in the spread of information, publicity or tactics; it also affects individual access to these resources: "actors who are connected to other prominent actors gain power through their positional ability to tap into larger stores of useful political information" (p. 13). Being able to perform a gate-keeping role within the network, or to access the actors performing that role, is of crucial importance in a number of political scenarios. In the case considered here -the emergence of collective actionit is important for three reasons: recruitment, partnership and mobilisation. Having the right position within a structure of connections will facilitate the recruitment of individuals, the establishment of alliances with other organisations and, as a consequence of both, the coordination of collective action and social mobilisation.

It is an empirical matter to establish whether civil society is articulated by competitive structures or, as social capital theory claims, by horizontal networks governed by relations of trust and reciprocity. Social capital research does not really provide empirical information on civic networks (it focuses, instead, on level of association as a proxy to the density of ties), but a good portion of the literature on social movements favours, under the name of resource mobilisation theory, the former view. This theory draws attention "to how the distribution of organizational resources may affect the role played by different actors in a network, in particular, whether more central actors owe their position to a greater control of resources" (Diani 2003b: 316). Having the financial and organisational resources to mobilise individuals is a fundamental prior condition in the construction of civic networks that social capital theory does not account for. A key task from this perspective is to "understand how organised groups acquire collective control over resources needed for challenging the authorities and how these resources are applied to affect social and political changes" (Knoke 1990: 67). In this process of acquisition of control, the recruitment of individuals plays a crucial role and organisations depend on their networks to execute it.

Networks have been said to perform a threefold function in the recruitment process: first, by socialising individuals and enhancing their disposition to participate; second, by generating the opportunities for participation; and third, by affecting the ultimate decision to take part (Passy 2003). According to this view, networks mediate at the beginning and at the end of the participation process: "at the beginning by building or reinforcing individual identities that create potential for participation, and at the very end when individual preferences and perceptions [...] eventually prompt people to take action" 
(Passi, 2003: 22). In the first phase, networks allow individuals to get ideologically closer to a given political issue; in the second, to be connected to opportunities for participation; and in the third, to access the information that will make them decide to join or not a collective action. In other words, networks allow potential participants to monitor others' actions and be influenced by them.

The influence that social networks have over individual decisions has been analytically explored by the critical mass theory (Marwell and Oliver 1993; Marwell and Prahl 1988; Oliver and Marwell 1988; Oliver, Marwell and Teixeira 1985). This theory is based on the idea that "some threshold of participants or action has to be crossed before a social movement 'explodes' into being" (Oliver, Marwell and Teixeira 1985: 523). The main assumption underlying this approach is that individual decisions are interdependent: they are sequential, and people take into account the actions previously taken by others when deciding how to act themselves. Yet networks not only provide the structure for that interdependence. They also influence the emergence of collective action by means of three of their features: their density, their centralisation and the costs of communicating across their ties (Marwell and Prahl, 1988: 505). It is centralisation -or how heterogeneous individuals are in their number of connections-what, according to these authors, generates the most relevant effect. When organising costs are high and resources are low, only some fraction of the agents to mobilise can be contacted; those agents whose contribution seems likely to be larger (because they are better connected) are preferred over the others, and this affects the speed and efficiency of the mobilisation process. As the authors say, "when resource heterogeneity is high, the number of others an organiser can afford to organise becomes much less significant as a constraint. If an organiser happens to have two or three big contributors in her network, she can achieve success without spending a lot of resources on organising" (p. 529). Since resources are scarce and connections costly, activating connections with those well connected brings higher outcomes for the same price. Yet this selectivity mechanism is based on networks that are closer to a hierarchy than to the horizontal structure so often assumed in civic networks.

One of the key concepts used by the critical mass theory -a threshold beyond which participation turns into collective action - was developed by Granovetter in the late 70 s (Granovetter, 1978). His threshold models are an approach to collective behaviour for situations where actors have two alternatives and the costs and benefits of each depend on how many other actors have chosen one of them. The concept of threshold, though, was not incorporated into an explicit model of networks until the mid nineties (Valente 1996). Rather than measuring thresholds in terms of how many others in the whole system follow a certain action, this approach measures thresholds as the number of others in the personal network that act in a certain way. In other words, it relaxes Granovetter's assumption of global information and complete connectedness, and introduces the concept of exposure to account for the proportion of actors in an individual's personal network that follow the behaviour at a given time; the threshold is the exposure at the time of adoption. 
The relevance of this differentiation -the relevance of making an explicit incorporation of networks in threshold models- is the realisation that individuals with the same thresholds may adopt at different times because their exposure is different (Valente: 1996:73). Two individuals with the same threshold but connected to networks of heterogeneous agents will not behave in a similar fashion: if individual $\mathrm{A}$ is connected to agents with low thresholds, she will act before individual $B$ if he is connected to agents that are themselves reluctant to act. Agents A and B share the same threshold (that is, they have the same propensity to join) but the time when their threshold is activated depends on their contacts and on their respective thresholds. Likewise, individuals connected to wider networks, like the agent in scenario A of Figure 1, will need a higher number of agents joining a course of action before deciding to do the same; this number will be higher than that required for an individual with the same threshold but connected to a smaller network: the larger the number of contacts an agent has, the more of these contacts will need to act before the agent overcomes her reluctance to join.

The effects that these network features have on the emergence of collective action are important because they shape contagious processes: different network structures have different effects on the rhythm and scope of social influence. Empirical analyses have shown that networks played a great role in, for instance, the growth and spread of trade unions in the early twentieth century Sweden. These findings suggest that "spatial properties and network densities are likely to influence considerably both the speed of a mobilisation process and the success of a movement in organising the relevant population" (Hedström, 1994: 1176). Networks, this approach implies, determine how and when thresholds are satisfied; and thresholds define the frontier between the initial slow growth phase and the phase of logistic growth that characterise contagious curves; that is, they define the turning point that need to be overcome to attain the critical mass (for a non-technical approximation see Gladwell 2001; for a general approach to the role networks play in contagion processes see Watts 2003: chapter 6). Whether a small initial influence ends up being a global movement depends on networks, on how they channel the diffusion of dynamics and contagion. Also on how they promote the flow of information and on whether they allow the emergence of the so-called informational cascades.

According to the cascade approach "each individual action [...] affects the information sets of other individuals who in the future may be either encouraged to take action or deterred from doing so" (Lohmann, 1994: 51). The informational cascade model states that collective action dynamics are generated endogenously by revealing information previously concealed; and it assumes that revelation comes by means of participation in public demonstrations, a turnout that needs to vacillate randomly: "if the number of political actions remains constant over time, no further information will be revealed, and consequently no individual will have incentives to turn out" (p. 54). The Monday demonstrations in Leipzig, which accelerated the collapse of the East German regime in 1989, stand as an example of this type of process: these demonstrations "publicly revealed some of the decentralised information about the malign nature of the East 
German regime and thereby created pressures for political liberalisation and reform" ( $p$. 91). When information is dispersed, networks contribute to merge its flow by opening access to what otherwise would be trapped in unconnected islands of individuals, which prompts more people to enrich the information flow and therefore reinforces the process in a feedback fashion. Briefly, "what all information cascades have in common [...] is that once one commences, it becomes self-perpetuating; that is, it picks up new adherents largely on the strength of having attracted previous ones" (Watts 2003: 206). The exact role that networks play in this process depends, again, on their structure.

The spread of information requires a trade-off between cohesion within groups and connections across them; that is, "a trade-off between local reinforcement and global connectivity" (p. 231), which is based on a distinction similar to that social capital theory makes between bonding (exclusive) and bridging (inclusive) ties (Putnam 2000: 22). The success of the Leipzig demonstrations were based on tightly knit clusters of individuals (churchgoers, groups of friends) but also on the more casual encounters with others that joined the demonstration along its route:

"We know from the diary of one of the regular demonstrators that small groups of friends typically met on Monday afternoons in the city center, where they would join churchgoers and other strangers to form a demonstration. They would then proceed along the Ringstrasse, which encircles the center of the town, picking up additional people along the way" (Lohmann 1994: 67-68)

Without those bridges or shortcuts overcoming the social distance between groups of closely related individuals, contagion processes and informational cascades cannot unfold. In their absence, networks can actually generate the opposite effect: an articulation of society around "concentric circles" (that is, clusters of ties with no external, bridging connections, Simmel [1908] 1955) or polarised groups, walled off from one another (Sunstein 2001).

Networks, then, contribute to the activation of collective action: they trigger endogenous mechanisms that traditional approaches to collective action, based on exogenous variables such as unemployment or other sources of relative deprivation, do not capture. There is large-scale empirical evidence about the role that those endogenous mechanisms play in the emergence of waves of contention (Biggs, 2005). These waves are based on mechanisms similar to those identified by threshold models, namely interdependence and positive feedback loops: "Positive feedback is inherent in the character of defiant collective action, because an individual's decision to participate is strongly influenced by the action of others" (Biggs,2005:1688). If, as this approach claims, strikes lead to further strikes it is because influence flows between individuals, which implies connections and therefore networks. And even if there is no interdependence (when the expected benefits, moral pressure, and costs of participation depend on the action taken by other individuals) networks still play their role by means of inspiration ( $p$. 1689). The informational cascade that took place during the Monday demonstrations in 
Leipzig was partly triggered by this inspiration mechanism: knowing that other citizens were protesting against the Regime encouraged more individuals to protest themselves, even though there was no direct connection or dependence between them other than common knowledge.

Why are networks, then, such a fundamental dimension in the articulation of collective action or the emergence of social norms? Because they provide the logistics to fulfil three crucial functions: the combination of different views, the prevention of concentrations of power, and the facilitation of civic mobilisation. But, as the literature reviewed so far shows, networks do not provide an unambiguous support to these functions. Competition between the different agents that form the network, the lack of heterogeneity in the resources available, or the absence of bridges connecting different groups are all elements that reflect on the structure of networks and therefore affect their functioning. Networks activate mechanisms that do not always benefit the plural and global diffusion of information, which in turn affects the decision of agents and the emergence of norms and collective action. The following section provides a more systematic account of the mechanisms that make networks, and their properties, so influential for social dynamics.

\section{Network Mechanisms and Social Outcomes}

Interdependence is the most basic mechanism by which networks affect social processes: it is connectedness what makes agents take into account the action previously taken by others and influence, in turn, other agents. This interdependence, though, takes different shapes and creates different structural positions: depending on the location within the global structure, agents will be able to activate (or not) the mechanisms that allow networks to fulfil a role within civil society. The previous section showed, for instance, that centralisation triggers a selectivity mechanism that enhances the efficiency of mobilisation processes: if agents $A$ and $B$ have resources to contact five other agents, but A's contacts are much more diversified in their connections (and, in particular, in their number of connections), then the reach and impact of A's call to mobilisation will be much wider. Another example was exposure, which influences the activation of thresholds by means of the structure of local networks: two agents with the same threshold will adopt a course of action, belief or idea at different times (and become an early-adopter or a follower) depending on their personal contacts, and on their own thresholds and connections. Network density was a third example of structural influence: the amount of connections in a network has an important impact on the speed of mobilisation processes because it affects how fast contagion unfolds; agents located in sparse networks have a clear disadvantage when it comes to promote mobilisation than agents located in denser networks. The right trade-off between cohesion within groups and connectivity across groups was, finally, another instance of how fundamental network properties are in promoting diffusion and cascades; again, due to this structural feature some agents (those connecting different groups) will play a preferential role over others. 
There are lots of studies that confirm, in other areas, the relevance of these and other network properties in the activation of social mechanisms. The literature on occupational mobility, for instance, also emphasises the significance of those connections that span social distance between groups. Having access to individuals embedded in different local communities (embedded in different local clusters within a network) opens opportunities for information that would not be available otherwise. And this, according to the literature, has clear advantages in processes like job hunting (Granovetter 1973; Granovetter 1995; also Flap and Boxman 2001; Lin, Cook and Burt 2001; Lin and Dumin 1986). The number of connections individuals have tells us how many sources of information these individuals can manage; and the strength of those connections, how diverse that information is: "those to whom we are weakly tied are more likely to move in circles different from our own and will thus have access to information different from that which we receive" (Granovetter 1973: 1371). Weak ties are the connections that link individuals who just meet occasionally, as opposed to friends and relatives, who are tied by much stronger ties. It is by virtue of those intermittent interactions that weak contacts become the sources of novel information, rich in new opportunities like, for instance, better jobs. Weak ties refer to the same network feature that the bridging ties identified by social capital literature, and play the same inclusive role.

Weak ties get their value from their ability to lay bridges across structural holes (Burt 1992; Burt 2005), a network feature that highlights the absence of connections between groups. Individuals spanning those holes have not only access to new sources of information but also the key to the control of its flow. Research on management networks has shown that this position actually grants a threefold competitive advantage to individuals: it provides an earlier access to information, a wider range of sources, and a better control over diffusion. In other words, the management of structural holes provides an opportunity for "the strategic deployment of information to create value" (Burt 2005: 17). This competitive advantage translates into better performance and better promotional outcomes: in the managerial arena, individuals who occupy brokerage positions get better evaluations, higher compensations and faster promotions in their careers (p. 36-7).

This very same research on management networks also highlights the importance that density has in promoting group cohesion and trust. When social ties among a group of individuals are dense, transitivity will also be higher: the denser a network, the closer everybody is to everybody else, and the higher the probability that someone's strong contacts will also be strongly connected among themselves. When this happens, the network is said to exhibit closure, which stands just at the opposite pole of the continuum leading to brokerage and structural wholes. Networks exhibiting this property have been said to promote trustworthiness and social norms in a much more efficient fashion than open structures (Coleman 1988), and this is so because sanctions and reputation can only work if there are proper channels for the flow of information that allow monitoring (and guiding) others' behaviour. It is precisely this feature what social capital theory echoes, as formulated by Putnam, when establishing the virtues of networks in generating 
endogenous mechanisms of regulation. In complex organisations, closure stands as an alternative source of value to structural holes: it brings major returns by making it safe to trust (Burt 2005: 97). Closure, and the cohesion it promotes, makes information redundant and rapidly available to everybody, which is clearly an advantage not only to build reputations but also to get a fast transmission of news or calls for mobilisation.

Structural equivalence stands as yet another network property able to affect contagious processes like those explored in the previous section. In a classical study on the diffusion of medical innovations, networks were found to have a significant role in the adoption of a new drug. The doctors better embedded in their professional community (those with more ties with other doctors) used the drug, on average, earlier than the doctors less connected (Coleman, Menzel and Katz 1957). In a later study, the influence of networks in that process was reassessed in the light of two structural features: cohesion and structural equivalence (Burt 1987). The main question the study aimed to answer was whether physicians resolved the uncertainty of adopting the new drug by discussing its advantages and disadvantages with colleagues (cohesion) or by looking at the action taken by those occupying similar positions in the social structure (structural equivalence). The influence of cohesion hinged on informal social pressure; the influence of structural equivalence, on competition between individuals occupying similar hierarchical positions. When influenced by cohesion, individuals managed uncertainty by discussing the innovation with others; when influenced by structural equivalence, they overcame uncertainty by following the desire to compete with equals (Burt, 1987:1291). According to the conclusions of the study, structural equivalence was the leading force in the adoption of the new drug.

More contemporary analyses have shown that this particular instance of innovation diffusion was actually driven by aggressive marketing efforts, rather than by contagion (van den Bulte and Lilien 2001). Yet this empirical finding does not invalidate the theoretical distinction between cohesion and structural equivalence: these two features promote the very same process but by means of very different mechanisms. Contagion by cohesion assumes that individuals choose under the influence of their advisers; contagion by structural equivalence assumes that individuals choose following their peers in the network hierarchy. While these two features generate the same effect (contagion and diffusion) they are based on mechanisms that entail a very different interpretation of risk, and a very different calculation of costs and benefits by the agents involved. A similar process might take place in the emergence of collective action, where instead of evaluating the adoption of a new drug, agents assess the costs and benefits of joining a particular course of action.

There are clear parallelisms in the literature on network mechanisms explored so far. Both occupational mobility and resource mobilisation theories highlight that some connections bring better resources than others. They draw attention to the fact that what waits at the other end of a connection is as important as the connection itself: the more resources in the hands of partners, the more resources will lie within reach. Ties, thus, carry a different weight depending on who sends them and who accepts to receive 
them. The closure argument, on the other hand, is reflected in Putnam's claim about the importance of networks for the generation of self-regulation devices such as trust, norms and sanctions. Both accounts see networks as horizontal structures where everybody is able to scrutinise and sanction everybody else, and where reputation and other sorts of information can travel fast. The role of density in processes of mobilisation and contagion is also reflected in the importance attributed to cohesion: it is in highly connected clusters where identities and group identification arise, and where coordination prevails over deviating actions. This is due to the enriched flow of information that transitivity provides -hence the importance of density to guarantee a good diffusion process. The opposite of cohesion and closure, structural holes, open, finally, the same opportunity for global diffusion than bridging ties: they are a precondition for bridges to play their role in connecting distant clusters in a network.

Networks create the opportunity to activate mechanisms that can impact the working of civil society. Yet their efficiency depends on what particular outcome is sought. Centralisation, for instance, facilitates civic mobilisation by means of the selectivity mechanism, but it goes against the function of preventing concentrations of power: the very same logic of this mechanism is based on a hierarchical structure. Additionally, centralisation might not promote the integration of diverse views if those who hold the key for a global connectivity are not activated properly. Bridges work to integrate parts of the network that would be unconnected otherwise: they work towards the integration of different views by providing agents with a better visibility, and also facilitate civil mobilisation to the extent that information is globally diffused. But their reverse, structural holes, also allow agents to play a brokerage role that they can use to their own advantage, which again, does not work in favour of preventing concentrations of power.

Exposure, in turn, depends not only on the structure and contents of local networks, but also on other global features such as structural equivalence. Exposure holds the key for the activation of thresholds, and therefore for the activation of mobilisation, but depending on what mechanism is at work -cohesion, based on neighbours, or competition, based on equals - the process will unfold more or less efficiently and, again, it might rely on a hierarchical structure rather than on a horizontal network. Finally, density and cohesion work on the assumption of horizontal structures and therefore do prevent concentrations of power while facilitating cooperation (and, potentially, mobilisation); but this is based on managing redundant information and explicitly excludes the function of merging diverse views. The efficiency of networks is thus filtered by the functions they are supposed to fulfil: it depends not only on their structural features, but also on the combination of these features. A definition of efficiency in line with that complexity is given in the following section.

\section{NetWork Efficiency}

A notion of efficiency has been implicitly used so far which is based on the ability of networks to spread information (or influence) faster, from a wider range of sources, 
and to a broader range of individuals. This section aims to build on that definition by elaborating three more claims: first, that the efficiency of networks does not depend on just one attribute (ie. density) but rather on the right trade-off between two types of structural features: those enhancing local cohesion (like closure or transitivity) and those promoting global connectivity (like bridges or structural holes); second, that efficiency cannot be assessed independently of the function: the efficiency of networks in preventing concentrations of power, by means of ties and alliances between organisations, does not necessarily match the efficiency of networks in merging a diversity of views; and third, that the functionality of networks can only be established taking into account the costs associated to their maintenance. This section claims that if we are to use a definition of efficiency to assess the role networks play in the articulation of collective action, this definition cannot be based on the theoretical claims that see networks as horizontal communities but rather on those that see them as structures that embody power and strategy.

The literature on complex networks provides the strongest basis for the first claim. This approach offers a systematic account of the structural properties that make some networks more efficient than others, that is, more robust and faster in transmitting information. Considering a diversity of structures that range from regular to random graphs (from networks where each node has the same number of connections that all the other nodes, to networks where the connectivity is completely arbitrary), this approach highlights the properties of those networks that lie in between the extremes, the so-called small world and scale-free networks.

What makes small-world networks so characteristic is that they display a similar clustering coefficient to regular networks whilst achieving a similar path length to random networks; in other words, they exhibit high local density (typical of regular networks) and low global distance (typical of random graphs). These two features refer to the very same properties under the names of closure or cohesion and bridges or structural holes. The combination of these two properties makes networks especially efficient for a number of processes that involve the transmission of information or the propagation of signals or behaviour (Watts and Strogatz 1998: 440; also Watts 1999a). First, given the smallworld nature of these networks, any one of the nodes are at a short distance from any other, where distance is measured as the number of links or connections that need to be crossed before two nodes can be linked (Buchanan 2002; Milgram 1967; Watts 2003). And second, this provides the key for their efficiency: the short average distance between any pair of nodes allows a fast global spread at the same time that the high clustering coefficient guarantees a fast local propagation.

The possibility space that small-world networks open is, however, still wide, with some of those graphs displaying very different degree distributions -or different levels of heterogeneity in the number of connections per node. Scale-free networks embrace those graphs where most nodes have only a few connections but are held together into the same structure by a few hubs that have a disproportionately higher connectivity (Barabási 2002: 70-71). These networks follow an uneven distribution of ties, they do not 
have an average node and therefore lack a representative scale of connectivity -hence their scale-free nature. Any pair of nodes in these networks is at a short distance because every node is only two or three steps away from a hub. Hubs are a minority of nodes that concentrate the majority of ties, and they are the key for the efficiency of these networks in the small-world sense (p. 135): since each hub is connected to a large number of other nodes, it has a high chance of receiving a piece of information that will be transmitted to an equally vast number of other nodes. These hubs or connectors are very similar in nature to the nodes identified by the selectivity mechanism in the critical mass theory.

Yet scale-free networks add a second element to the notion of efficiency: robustness. Scale-free networks display a higher robustness to failures thanks to their hub-based architecture: failures "do not discriminate between nodes but affect small nodes and large hubs with the same probability [...] Therefore, if failures in networks affect with equal chance all nodes, small nodes are far more likely to be dismantled, since there are many more of them" (p. 113-114). In the event of random failure, hubs, in their minority, go unnoticed far more frequently than the rest of the nodes, increasing the network resilience to errors (this feature is, of course, a flaw rather than a virtue when the causes of disruption are intentional and not-random). At the same time, the costs associated to the creation and maintenance of ties are reduced without losing the smallworld properties: the total count of ties in scale-free networks is smaller: only a few hubs need to be highly connected; but the global connectivity is equally enhanced. Scale-free networks do not only have a higher robustness; they are also the cheapest way of getting resistance (to random failure) in a small world.

The relevance of these models, summarised in Table 1, is twofold. First, they contribute to build a general theory of networks in which to embed the RAT models (Goyal 2007). Cooperation games like the prisoners dilemma generate different results when agents interact in this type of networks as opposed to regular or random networks (a common assumption in the literature on game theory but empirically unrealistic). Second, these models provide an important benchmark to compare the efficiency of networks. This approach turns networks into structures that can be optimised to increase value and reduce the "logistic costs" associated to their maintenance. This highlights an aspect too often disguised in the claims made about the importance of networks in civil society: that growing and maintaining links is beneficial, but also costly, particularly when resources are scarce. As already mentioned before, features such as the heterogeneity of connections within a network is an advantage under resource constraints: having the opportunity to access agents with a greater impact of reach in a global structure of ties (the hubs, the brokers) becomes an asset in terms of diffusion and mobilisation.

What this approach to networks tells us, then, is that efficiency is not independent of costs; yet what it does not say, as resource mobilisation theories did, is that costs, or rather the ability to face them, are usually not the same for all the agents involved. Agents have different stocks of resources, and networks reflect their different strategies, interests and bargaining positions; that is, they reflect an asymmetrical distribution of power. Social networks are not decentralised, invisible-hand systems: they emerge in 
Table 1.

Elements of Network Efficiency.

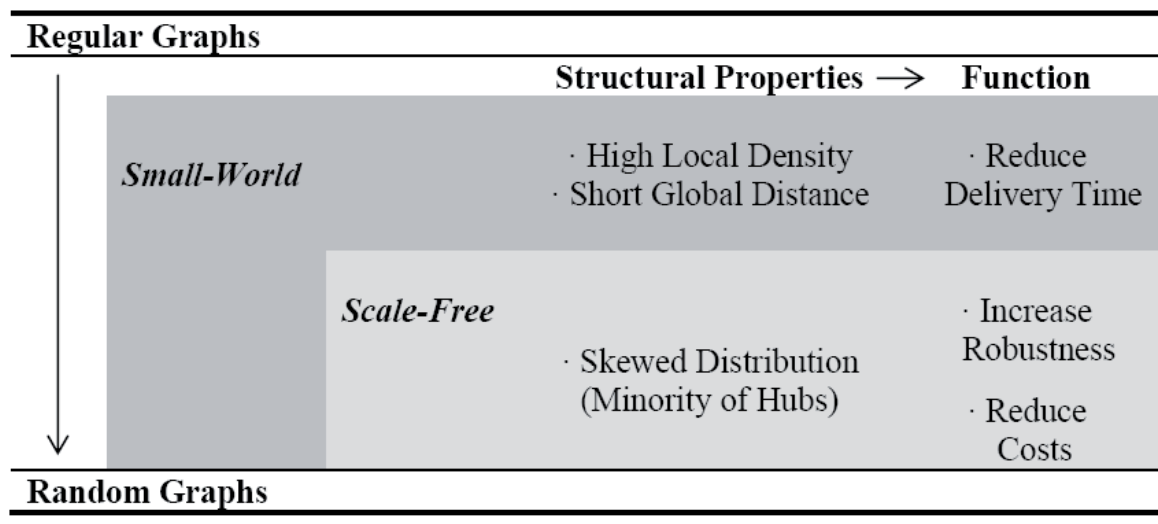

a context that precedes them and which will determine their structure. A lot has been said about how the Internet and new communication technologies have relaxed these old dependencies by reducing the costs associated to the public function and granting a more egalitarian access to new forms of communication. The emergence of the Zapatista movement or the anti-globalisation protests that erupted in 1999 are two of the examples most often used in the literature to illustrate the positive impact of new technologies in articulating collective dynamics. The last two US presidential elections, where web technologies contributed greatly to shape the campaigns, is another example of how networks are becoming more relevant (and more visible) under the influence of the Internet. The following section aims to assess some of the claims made in the literature about the impact that ICTs are having on collective action, and determine to what extent they are changing the way social networks operate.

\section{The Impact OF the INTERNET ON THE EFficiency OF NetWORKS}

Most of the claims made in the literature about the changes brought about by the Internet have to do with how it has affected the scope and effectiveness of the mechanisms identified so far. If "the forms and contents of information exchanges shape the capacity of individuals and groups to influence collective decisions" (Knoke 1990: 205), then the Internet has allowed reaching levels of influence never achieved before. Local initiatives can now be echoed globally, and disseminating information is much cheaper and faster: "the explosive growth of connectivity via the Internet alters the transmission of information among networks, shrinking costs, maximising speed, broadening reach, and eradicating distance" (Norris 2001: 20). In this new environment of "minimal-cost" and 
"instantaneous global communications", networks are said to play a more efficient role in widening individual exposure to information.

First, interdependence now embraces more people than ever as connectedness is increasingly being less constrained by geographical proximity (Castells 2004a). If the action taken by other individuals matters when deciding what course of action to take, now the points of reference have grown along with the new methods for diffusing and accessing information. New technologies have changed "the geographical scope of the media and consequently alter the construction of collective identities. The globalization of information flows enlarges the group of people concerned" (Chambat 2000: 268). In other words, new technologies have multiplied the elements involved in the calculations that individuals make prior to their civic involvement. The number of others to which one is potentially connected is now larger, and information -the bullet points in the public agenda - is more diversified than ever.

The shape of interdependence has, according to the literature, also changed: given the architecture of the Internet, civic networks can now become more decentralised and horizontal (Chadwick 2006: 22). As some have put it, it is not only that recent mass protests, like those against globalisation, "would have been impossible without the Internet"; it is also that "the communication technology that facilitates these campaigns is shaping the movement in its own image", allowing the emergence of "an activist model that mirrors the organic, decentralized, interlinked pathways of the Internet" (Klein 2002: 266). The constant exchange of information and the minimal costs associated to it are said to promote the establishment of ad hoc alliances that can evolve into more stable coalitions without requiring strict consensus or bureaucratic hierarchies. Density increases and, with that, the number of channels of communication and influence which, according to these theories, hampers the centralisation of resources: "the Net's built-in resistance to centralized control makes it inherently more egalitarian and democratic than other forms of mass media" (Kolko 2003: 28). New technologies, these claims go, allow knitting denser and more horizontal networks, which provides all players with a fairer position to draw attention to their cause and have an impact.

However, none of these studies provides a robust empirical ground in which to root their enthusiasm; and, given the lack of empirical evidence, it is difficult to discern whether these claims are about technical possibilities or about actual usage. In fact, more recent approaches water down this optimistic view: "the professionalisation of web-based politics has massively increased costs since the early days of the mid-1990s, and though it is relatively simple to establish a website, this is no guarantee that users will flock to it" (Chadwick 2006: 23). The Internet provides the technical means to facilitate the diffusion of information and access to it, but it does not provide a guarantee that these possibilities will benefit all agents to the same extent.

The media has always been considered to play an important role in the activation of collective action because of its impact on diffusion and contagious processes. Traditional media, though, could only contribute to spread influence in places where people had access to their news and broadcast: events taking place in areas not covered by local 
media stations were invisible, of null impact (Myers, 2000). These media gaps, either intentional or unintended, created firebreaks in the emergence of collective action that, according to the literature, have been minimised by the range of visibility that the Internet enables. The message of an uprising Zapatista movement, for instance, was projected globally, reaching the media focus of every major country in the planet, from the rather remote soil of the Mexican state of Chiapas (Cleaver ,1998; Shepard and Hayduk, 2002; Castells, 2004b: 75-87; Bob, 2005: 117-177). The anti-globalisation movements -which, for many, provide the ultimate evidence of the impact that the Internet has had on civil society - were greatly inspired by this indigenous struggle, and identified with many of their claims, despite these being rooted in very local circumstances which, in other times, would have been invisible to most.

If the influence of the media depends on how it is distributed and accessed, then the Internet has made an unequivocal contribution to increase the efficiency of networks. And this has had a positive influence on the coordination of mobilisation and collective action since it enables individuals "to find multiple points of entry into varieties of political action" (Bennett, 2003: 144). The combination of lower costs and higher exposure contributes to activate thresholds and spread actions in a faster and more efficient fashion, a possibility that has been realised in a number of occasions. The International Campaign to Ban Landmines, which was awarded with the Nobel Peace Prize in 1997, stands as an already classic example of how the Internet has increased the speed and efficiency of group mobilisation (Hajnal 2002: chapter 5; Klotz 2004: 86-7). The campaign attained an international treaty banning landmines just after six years of its foundation in 1991. At the individual level, the most salient examples of Internet mobilisation revolve around protests against global trade. At the 1999 World Trade Organisation meeting, for instance, "Seattle police admit[ted] being unprepared for the level of Internet-enhanced coordination of 45.000 protesters" (Klotz 2004: 87). The episodes of mass protests where the Internet has played a crucial role have multiplied in the last years in a number of countries (Castells et al., 2006); and the impact of web technologies in formal politics has contributed to shift the balance of power amongst traditional actors (Castells 2009). The Internet and related technologies have increased the speed and efficiency required for the successful coordination of individual actions. This coordination would have required more time and many more resources had not been for the network logistics provided by electronic forms of communication. And, this paper has argued, only a theory of networks can explain the success (or failure) of the collective dynamics sustained by these new platforms of interaction.

\section{CONCLUSION}

If people are influenced by what others do, "the Internet is an obvious breeding ground for cascades" (Sunstein 2001: 84): it has optimised the networks connecting individuals by widening the scope of communication and reducing the costs associated to it. The emergence of the Internet has made more explicit than ever the relevance that networks 
have in the articulation of social phenomena like collective action. If we do not take into account the structure that links individuals, and how that structure unleashes mechanisms of social influence, it will not be possible to explain satisfactorily the emergence of norms and collective action - even less in the scenario opened up by new technologies which, as the previous section illustrated, presents already some examples difficult to explain exclusively in the terms proposed by the RAT. This paper has presented some conceptual tools that can help us provide a more satisfactory explanation of these empirical phenomena.

One of the advantages of analysing Internet-based interactions is that they provide observational network data with a resolution that was previously very difficult, if not impossible, to get (Watts, 2007). Using this data we can develop models that not only capture the structural properties of whole systems of interaction but also their evolution over time, which can give us unprecedented insight into the mechanisms that underlie their dynamics (see, for instance, Lewis et al., 2009). But using electronic data also creates new challenges that we need to solve to incorporate their analysis into our theoretical understanding of collective phenomena. These challenges have to do with measurement and validity issues (i.e. how do online networks differ from offline networks, or how do they relate to each other) but also with problems of identity and privacy (i.e. how do we know if online users are who they claim to be). On this methodological level, we need to devise protocols that can help us standardise research on online phenomena. But, perhaps most importantly, we also need to redefine the models that, on a theoretical level, see individuals as isolated decision-makers, and insert them in structures of interaction able to reproduce empirical patterns. Under the influence of new technologies, networks are becoming not only more relevant but also more visible and tangible for researchers. This paper has presented the theoretical tools that can help us advance our understanding of how these networks work.

\section{References}

Aguiar, F. 1990. "La lógica de la cooperación”. Zona Abierta 54-55:7-41.

Axelrod, R. 1984. The Evolution of Cooperation. New York: Basic Books.

Barabási, A.L. 2002. Linked. The New Science of Networks. Cambridge, MA: Perseus.

Bennett, W.L. 2003. "Communicating Global Activism: Strengths and Vulnerabilities of Networked Politics." Information, Communication \& Society 6:143-168.

Biggs, M. 2005. "Strikes as Forest Fires: Chicago and Paris in the late nineteenth century", American Journal of Sociology, 110:1684-1714.

Bob, C. 2005. The Marketing of Rebellion. Insurgents, Media, and International Activism Cambridge: Cambridge University Press. 
Buchanan, M. 2003. Small World: Uncovering Nature's Hidden Networks. London: Phoenix.

Burt, R.S. 1987. "Social Contagion and Innovation: Cohesion versus Structural Equivalence." American Journal of Sociology 92:1287-1335.

Burt, R.S. 1992. Structural Holes. The Social Structure of Competition. Cambridge, MA: Harvard University Press.

Burt, R.S. 2005. Brokerage and Closure. An Introduction to Social Capital. Oxford: Oxford University Press.

Castells, M. (ed.) 2004a. The Network Society. A cross-cultural perspective. Cheltenham: Edward Elgar.

Castells, M. 2004b. The Power of Identity. Oxford: Blackwell.

Castells, M. 2009. Communication Power. Oxford: Oxford University Press.

Castells, M., M. Fernandez-Ardevol, J. Linchuan-Qiu and A. Sey. 2006. "Electronic communication and sociopolitical mobilisation: a new form of civil society", Global Civil Society 2005/6, edited by Marlies Glasius, Mary Kaldor, and Helmut Anheier. London: Sage Publications.

Cleaver, H.M. 1998. "The Zapatista Effect: the Internet and the Rise of an Alternative Political Fabric". Journal of International Affairs 51:621-40.

Coleman, J.S. 1988. "Social Capital in the Creation of Human Capital". American Journal of Sociology 94:S95S120.

Coleman, J.S. 1990. Foundations of Social Theory. Cambridge, Mass.: Belknap Press of Harvard University Press.

Coleman, J.S., H. Menzel and E. Katz. 1957. "The diffusion of an innovation among physicians", Sociometry, 20:253-270.

Chadwick, A. 2006. Internet Politics. States, Citizens, and New Communication Technologies. New York: Oxford University Press.

Chambat, P. 2000. "Computer-Aided Democracy: The Effects of Information and Communication Technologies on Democracy." in The Information Society in Europe. Work and Life in an Age of Globalization, edited by Ken Ducatel, Juliet Webster, and Werner Herrmann. Oxford: Rowman \& Littlefield.

Diani, M. 2003. "Networks and Social Movements: a Research Programme", in Social Movements and Networks. Relational Approaches to Collective Action, edited by Mario Diani and Doug McAdam. New York: Oxford University Press.

Elster, J. 1989. The Cement of Society. Cambridge: CUP, Cambridge University Press.

Flap, H. and Ed. Boxman. 2001. "Getting Started: the Influence of Social Capital on the Start of the Occupational Career." in Social Capital. Theory and Research, edited by Nan Lin, Karen Cook, and Ronald S. Burt. New York: Aldine de Gruyter.

Gilbert, N.I and K. Troitzsch. 2005. Simulation for the Social Scientist. Maidenhead: Open University Press. 
Gladwell, M. 2001. The Tipping Point. How little things can make a big difference. London: Abacus.

Goyal, S. 2007. Connections. An Introduction to the Economics of Networks. Princeton, NJ: Princeton University Press.

Granovetter, M. 1973. "The strength of weak ties". American Journal of Sociology 78:1360-1380.

Granovetter, M. 1978. "Threshold Models of Diffusion and Collective Behaviour", Journal of Mathematical Sociology 9:165-179.

Granovetter, M. 1995. Getting a Job: A Study of Contacts and Careers, 2nd Edition. Chicago, IL: University of Chicago Press.

Hajnal, P.I. (ed.) 2002. Civil Society in the Information Age. Aldershot: Ashgate.

Hardin, R. 1982. Collective Action. Baltimore, Maryland: John Hopkins University Press.

Hedström, P. 1994. "Contagious collectivities: on the spatial diffusion of Swedish trade unions, 1890-1940". American Journal of Sociology 99:1157-79.

Klein, N. 2002. "The vision thing: were the DC and Seattle protests unfocused, or are critics missing the point?" in From Act Up to the WTO: Urban Protest and Community Building in the Era of Globalization edited by Benjamin Shepard and Ronald Hayduk. New York: Verso.

Klotz, R.J. 2004. The Politics of Internet Communication. Lanham: Rowman \& Littlefield.

Knoke, D. 1990. Political Networks. The Structural Perspective. New York: Cambridge University Press.

Kolko, B.E. (ed.) 2003. Virtual Publics. Policy and Community in an Electronic Age. New York: Columbia University Press.

Lewis, K., J. Kaufman, M. Gonzalez, A. Wimmer and N.A. Christakis. 2009. "Tastes, Ties, and Time: A New Cultural, Multiplex, and Longitudinal) Social Network Dataset Using Facebook.com" Social Networks, 30: 330-342.

Lin, N., K. Cook and R.S. Burt (eds.) 2001. Social Capital: Theory and Research. New York, NY: Aldine de Gruyter.

Lin, N. and M. Dumin. 1986. "Access to Occupations Through Social Ties", Social Networks. 8:365-385.

Linares, F. 2004. "Hawks, Zealots and Hypocrites but not Free Riders: the logics of cooperation in Llano del Beal". Rationality and Society 16:437-476.

Lohmann, S. 1994. "Dynamics of Informational Cascades: the Monday Demonstrations in Leipzig, East Germany, 1989-1991". World Politics 47:42-101.

Marwell, G. and P. Oliver. 1993. The Critical Mass in Collective Action. Cambridge: Cambridge University Press.

Marwell, G. and R. Prahl. 1988. "Social networks and collective action. A theory of critical mass III." American Journal of Sociology 94:502-34. 
Milgram, S. 1967. "The Small World problem." Psychology Today. 2:60-67.

Miller, L.M. 2007. "Coordinación y Acción Colectiva”. Revista Internacional de Sociología. 46:161-183.

Myers, D.J. 2000. "The Diffusion of Collective Violence: infectiousness, susceptibility, and mass media networks". American Journal of Sociology. 106:173-208.

Norris, P. 2001. Digital Divide: Civic Engagement, Information Poverty, and the Internet Worldwide. Cambridge: Cambridge University Press.

Oliver, P. and G. Marwell. 1988. "The paradox of group size in collective action: a theory of critical mass II". American Sociological Review. 53:1-8.

Oliver, P., G. Marwell and R. Teixeir. 1985. "A theory of the critical mass. I. Interdependence, group heterogeneity, and the production of collective action". American Journal of Sociology. 91:522-56.

Olson, M. 1965. The Logic of Collective Action: public goods and the theory of groups. Cambridge, MA: Harvard University Press.

Passy, F. 2003. "Social Networks Matter. But How?", Social Movements and Networks. Relational Approaches to Collective Action, edited by Mario Diani and Doug McAdam. New York: Oxford University Press.

Paxton, P. 1999. "Is Social Capital Declining in the United States? A Multiple Indicator Assessment". American Journal of Sociology. 105:88-127.

Paxton, P. 2002. "Social Capital and Democracy: an Interdependent Relationship". American Sociological Review. 67:254-277.

Putnam, R.D. 1995. "Bowling Alone: America's Declining Social Capital." Journal of Democracy. 6:65-78.

Putnam, R.D. 2000. Bowling Alone. The collapse and revival of American community. New York, NY: Simon and Schuster.

Shepard, B. and R. Haydu. 2002. From Act Up to the WTO. Urban protests and community building in the era of globalization. New York: Verso.

Simmel, G. [1908] 1955. "The web of group affiliations". In Conflict. The web of group affiliations. New York: Free Press.

Sunstein, C. 2001. Republic.com. Princeton, NJ: Princeton University Press.

Ullmann-Margalit, E. 1977. The Emergence of Norms. Oxford: Oxford University Press.

Valente, Th.W. 1996. "Social network thresholds in the diffusion of innovations". Social Networks. 18:69-89.

Van den Bulte, Ch. and G.L. Lilien. 2001. "Medical Innovation Revisited: Social Contagion versus Marketing Effort". American Journal of Sociology. 106:1409-35.

Watts, D.J. 1999. "Networks, Dynamics and the Small World Phenomenon". American Journal of Sociology. 105: 493-527. 
Watts, D.J. 1999. Small Worlds. The Dynamics of Networks between Order and Randomness. Princeton, NJ: Princeton University Press.

Watts, D.J. 2003. Six Degrees. The Science of a Connected Age. London: William Heinemann.

Watts, D.J. 2007. "A twenty-first century science". Nature. 445: 489.

Watts, D.J. and S.H. Strogatz 1998. "Collective dynamics of 'small world' networks". Nature. 393:440-442.

SANDRA GONZALEZ BAILON is a PhD (DPhil) in Sociology at the University of Oxford, with a thesis entitled "Mapping Civil Society on the Web: Networks, Alliances, and Informational Landscapes" (2007). She currently holds a Research Fellowship at the Oxford Internet Institute and Nuffield College. She is also a member of the research team GSADI (Grupo de Investigacion en Sociologia Analitica y Diseno Institucional - Research Group on Analytical Sociology and Institutional Design) from the Universidad Autonoma de Barcelona.

\section{RECEIVED: 14 April 2008}

ACEPPTED: 26 June 2008

Published online: 27 May 2009 